\title{
Degeneración sarcomatosa de malformación arteriovenosa Sarcomatous degeneration arteriovenous malformation
}

\section{Ruth Fuente-Garrido1,*, Enrique María San Norberto-García², Cintia Flota-Ruiz ${ }^{1}$, Miguel Martín-Pedrosa ${ }^{2}$, Álvaro Revilla-Calavia ${ }^{2}$ y Carlos Vaquero-Puerta ${ }^{3}$}

\author{
${ }^{1}$ Médico Residente; ${ }^{2}$ Facultativo Especialista; ${ }^{3}$ Catedrático, Jefe de Servicio. Servicio de Angiología y Cirugía Vascular, \\ Hospital Clínico Universitario, Valladolid, España
}

Recibido el 30 de abril de 2016; aceptado el 25 de febrero de 2017

Disponible en Internet el 4 de agosto de 2017

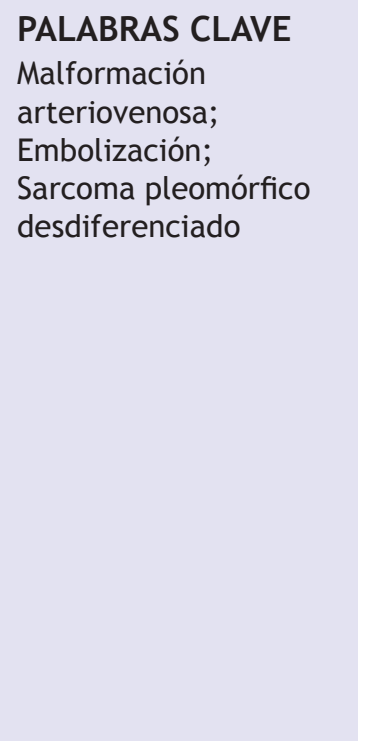

Resumen La prevalencia de malformaciones vasculares se estima en el $1.5 \%$ en la población general. Los sarcomas son un grupo raro de tumores malignos de origen mesenquimal que representa menos del $1 \%$ de todos los tumores del adulto. Presentamos un caso de degenera. ción sarcomatosa en una malformación arteriovenosa de 50 años de evolución. Paciente de 69 años de edad que ingresa en nuestro servicio por infección de partes blandas y sangrado en retropié en el contexto de una malformación arteriovenosa de más de 50 años de evolución de etiología no filiada. Presenta pulsos distales bilaterales. En la extremidad inferior derecha se observa lesión ulcerada y sobreinfectada de $5 \times 6 \mathrm{~cm}$ en retropié que presenta en sus bordes formaciones mamelonadas que se colapsan a la presión con el dedo. La arteriografía diag nóstica objetiva una formación vascular con nido angiomatoso en la superficie medial de la articulación tibio-peroneo-astragalina dependiente de la arteria tibial posterior. Se emboliza la malformación arteriovenosa con total exclusión de la misma en el control final. A pesar del tratamiento médico y las curas persiste la mala evolución, con sobreinfección y aparición de nuevos mamelones, por lo que se decide realizar una amputación infracondílea. La anatomía patológica revela una neoplasia mesenquimal maligna sugestiva de sarcoma pleomórfico des-o diferenciado con células gigantes (histiocitoma fibroso maligno de tipo células gigantes). EE paciente fallece a los 3 meses del diagnóstico por diseminación de la enfermedad tumoral. La degeneración sarcomatosa es una complicación rara de las malformaciones arteriovenosas, y ante la baja sospecha clínica se demora el diagnóstico, lo que conlleva malos resultados a corto plazo. (creativecommons.org/licenses/by-nc-nd/4.0/).

${ }^{*}$ E-mail para correspondencia: ruth.fuente.garrido@gmail.com (R. Fuente-Garrido) 


\section{INTRODUCCIÓN}

La prevalencia de malformaciones vasculares se estima en el $1.5 \%$ en la población general ${ }^{1}$. En las malformaciones arteriovenosas (MAV) son características las comunicaciones anormales entre el sistema arterial y el sistema venoso. Los sarcomas son un grupo raro de tumores malignos de origen mesenquimal que representan menos del $1 \%$ de todos los tumores del adulto ${ }^{2,3}$. Presentamos un caso de degeneración sarcomatosa en una MAV de 50 años de evolución.

\section{CASO CLÍNICO}

Paciente varón de 69 años de edad que ingresa en el servicio de angiología y cirugía vascular por presentar infección de partes blandas y sangrado en el retropié en el contexto de una MAV de más de 50 años de evolución de etiología no filiada. El paciente es exfumador y tiene antecedentes personales de hipertensión arterial y cáncer urotelial de vejiga tratado mediante resección transuretral.

A la exploración presenta pulso pedio y tibial posterior en ambas extremidades inferiores. En la extremidad inferior derecha se observa una lesión ulcerada y sobreinfectada de $5 \times 6 \mathrm{~cm}$ en el retropié que tiene en sus bordes formaciones mamelonadas que se colapsan a la presión con el dedo y que presentan sangrado en sábana esporádico (Fig. 1 A).

El paciente es tratado con antibioticoterapia intravenosa según antibiograma y curas locales. La arteriografía diagnóstica objetiva aumento de la velocidad de tránsito en el sistema arterial del miembro inferior derecho con respecto al contralateral, y se observa una formación vascular con nido angiomatoso en la superficie medial de la articulación tibio-peroneo-astragalina y aferente tributaria principal de la arteria tibial posterior.

Bajo anestesia raquídea y acceso femoral derecho $6 \mathrm{~F}$, se canaliza la arteria tibial posterior. La arteriografía intraoperatoria evidencia una MAV dependiente de la arteria tibial posterior (Fig. 2 A). Se emboliza la malformación arteriovenosa con Glubran 2 acrylic glue (GEM, Viareggio, Italia), con total exclusión de la MAV en el control final (Fig. 2 B). Posteriormente se realiza Friedrich quirúrgico de la úlcera y se toma muestra de los bordes para estudio anatomopatológico. Tras la intervención quirúrgica, la lesión presenta mejoría, por lo que el paciente es dado de alta. Al mes de la intervención, el paciente reingresa por el mismo cuadro. Se realiza un segundo desbridamiento quirúrgico de la herida, practicando exéresis completa de la misma. A pesar del tratamiento antibiótico y las curas compresivas locales, el lecho quirúrgico presenta mala evolución, con persistencia de la infección y aparición de nuevos mamelones, por lo que se decide realizar una amputación infracondílea.

La anatomía patológica revela una neoplasia mesenquimal maligna infiltrante que ulcera la epidermis, extensamente necrotizante y que alcanza los planos subcutáneo y muscular estriado esquelético. Las células tumores expresan vimentina y localmente actina de músculo liso, las células gigantes expresan CD68 y se observa un índice proliferativo del 40\% (Ki-67). El diagnóstico anatomopatológico es de neoplasia mesenquimal maligna sugestiva de sarcoma pleomórfico desdiferenciado con células gigantes (histiocitoma fibroso maligno de tipo células gigantes).

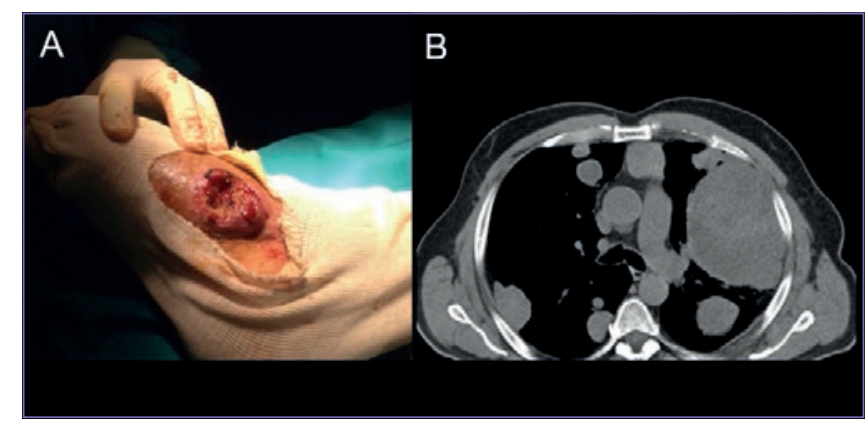

Figura 1. A: Hallazgos operatorios: lesión excreciente con sangrado en sábana. B: Corte transversal de tomografía computarizada de tórax en el que se observan metástasis sarcomatosas pulmonares (patrón en suelta de globos).

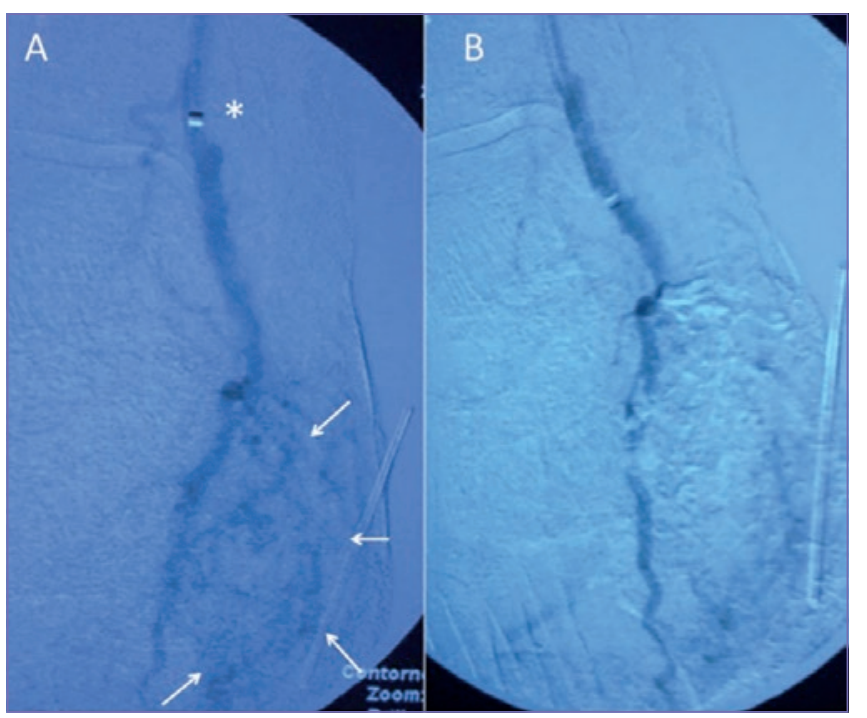

Figura 2. A: Arteriografía intraoperatoria previa a la embolización: malformación arteriovenosa (flechas) dependiente de arteria tibial posterior donde se ha posicionado un catéter para embolización (asterisco). B: Control arteriográfico final en el que se aprecia la correcta embolización de la malformación.

El paciente es referido a oncología y a los 2 meses del diagnóstico anatomopatológico ingresa en el servicio de medicina interna por cuadro de disnea progresiva de 2 semanas de evolución. La radiografía de tórax revela un patrón en suelta de globos. Los hallazgos se corroboran en una tomografía computarizada de tórax que muestra metástasis pulmonares (Fig. 1 B). El paciente fallece a los 3 meses del diagnóstico por progresión de la enfermedad tumoral.

\section{DISCUSIÓN}

Después del tumor del estroma gastrointestinal, los tumores mesenquimales más frecuentes del adulto son los sarcomas desdiferenciados, como el que presentamos, seguidos del liposarcoma y el leiomiosarcoma.

Las MAV constituyen un reto terapéutico debido a su impacto en el sistema cardiovascular y a las alteraciones hemodinámicas que se derivan de ello ${ }^{4}$. Las manifestaciones clínicas de las MAV dependen de su localización y pueden producir insuficiencia cardiaca congestiva, hipertensión venosa e insuficiencia venosa o arterial, y como consecuencia de estas últimas, 
ulceración cutánea e incluso gangrena ${ }^{5}$. El desarrollo de los síntomas está causado por un incremento del shunt que produce robo en el sistema arterial e hipertensión en el sistema venoso, produciendo como consecuencia una reducción de la perfusión tisular, lo que lleva a dolor, ulceración y sangrado ${ }^{4}$. Existen cuatro indicaciones para el tratamiento quirúrgico: sangrado, complicaciones derivadas de la hipertensión venosa, lesión localizada en una región anatómica que ponga en peligro la vida del paciente (p. ej., cerca de la vía aérea) o que afecte a funciones vitales (p. ej., oído, vista...). El dolor, la incapacidad funcional y la infección recurrente se incluyen, entre otras, en las indicaciones relativas ${ }^{6}$. El tratamiento de las MAV tiene como objetivo el cierre de las comunicaciones arteriovenosas mediante cirugía convencional o técnicas endovasculares. Actualmente, la embolización transarterial de la arteria nutricia es la primera opción terapéutica ${ }^{7}$.

Los tumores mesenquimales se presentan como tumoraciones indoloras de crecimiento lento. Cuando el tumor alcanza un tamaño importante, pueden aparecer dolor o síntomas asociados a la compresión, como edema o parestesias en la extremidad. El $46 \%$ de los sarcomas se encuentran en las extremidades inferiores (glúteos, ingles y miembro inferior $)^{8}$. Aunque se desconoce su etiología, hay factores que predisponen a la aparición de sarcomas, como la genética, Li Fraumeni, neurofibromatosis tipo $I^{9}$, tratamiento con radioterapia o quimioterapia, linfedema crónico (posquirúrgico, filariasis...) e irritación crónica. Es posible que, en el caso que nos interesa, la persistencia de la fístula arteriovenosa durante 50 años haya podido desempeñar algún papel en el desarrollo del sarcoma.

\section{CONCLUSIÓN}

La degeneración sarcomatosa es una complicación rara de las malformaciones arteriovenosas, y ante la baja sospecha clínica suele demorarse el diagnóstico, lo que conlleva malos resultados a corto plazo.

\section{BIBLIOGRAFÍA}

1. Eifert S, Villavicencio L, Kao TG, et al. Prevalence of deep venous anomalies in congenital vascular malformations of venous predominance. J Vasc Surg. 2000;31:462-71.

2. Siegel RL, Miller KD, Jemal A. Cancer statistics, 2015. CA Cancer Clin. 2015;65:5-29.

3. Miller RW, Young JL Jr, Novakovic B. Childhood cancer. Cancer. 1995; 75:395-405.

4. Lee BB, Baumgartner I, Berlien HP, et al. Consensus document of the international union of angiology (IUA)-2013. Current concept on the management of arterio-venous malformations. Int Angiol? 2013;32:9-36.

5. Simkin R. Varices, úlceras y angiodisplasias. Buenos Aires: López Libre ras Editores; 1991. p. 429-51.

6. Lee BB. New approaches to the treatment of congenital vascular malformations (CMVs): a single centre experience. Eur J Vasc Endovasc Surg. 2005;30:184-97.

7. Gloviczki P, Duncan A, Kalra M, et al. Vascular malformations: an up date. Perspect Vasc Surg Endovasc Ther. 2009;21:133-48.

8. Lawrence W Jr, Donegan WL, Natarajan N, et al. Adult soft tissue sarcomas. A pattern of care survey of the American College of Surgeons. Ann Surg. 1987;205:349-59.

9. Zahm SH, Fraumeni JF Jr. The epidemiology of soft tissue sarcoma Semin Oncol. 1997;24:504-14. 